\title{
A further prevalence study of multiple sclerosis in north-east Scotland
}

\author{
DAVID I SHEPHERD AND ALLAN W DOWNIE
}

From the Department of Medicine, Aberdeen University, Aberdeen

SUMMARY A second epidemiological study of multiple sclerosis (MS) in north-east Scotland has confirmed that the area has the highest prevalence rate in the world for any population of comparable size. On 1 December 1973 the prevalence was 144 per 100000 population. The age and sex specific prevalence rates are the highest ever recorded, one in every 306 of the population aged 40 to 59 years being affected. All patients have been tabulated in the National Health Service Central Register to facilitate future studies. The MS mortality rate in north-east Scotland is similar to the rate for the whole of Scotland. Throughout most of Scotland, therefore, MS probably is as prevalent as it is in the north-east.

We have previously reported that in north-east Scotland on 1 December 1970, the prevalence of MS was 127 cases per 100000 population. ${ }^{1}$ Thus the disease was more common than in any other surveyed area with a comparable population. We undertook a further study on 1 December 1973, to establish a new prevalence rate, to identify patients overlooked in the first study and to establish a register of MS patients tabulated at the General Register Office for Scotland. Patients were studied according to area in which they were living on 1 December 1973, according to birthplace and according to main residence during childhood.

\section{Methods}

The area studied consisted of the City of Aberdeen and counties of Aberdeen, Kincardine, Moray and Banff and was identical to that of the 1970 study. We used the same diagnostic categories of probable MS, early and latent probable MS and possible MS. The 1970 series formed the basis of the second study. Any patients diagnosed between 1970 and prevalence day 1 December 1973 were added and information on all these patients was arranged into appropriate practices and submitted to the individual general practitioners. Once again a complete response was achieved and on this

Address for reprint requests: Dr David I Shepherd, Department of Neurology, North Manchester General Hospital, Crumpsall, Manchester M8 6RB.

Accepted 8 November 1979 occasion the general practitioners were able to add a further 18 patients to the final total. Some patients in the first series had died, a few had left the area and the diagnosis of MS was now unacceptable in five. However, a formal diagnostic reappraisal of all patients surviving from the 1970 study was not undertaken. In the whole series $83 \%$ of patients had been examined by a neurologist and this included all patients added since 1970.

We used the same geographical units ${ }^{1}$ for dividing the region into 28 areas for the study of prevalence by area of residence on prevalence day and the population figures from the 1971 Census. ${ }^{2}$ The 1921 Census figures were again used for area of birthplace and the 1931 Census $^{3}$ for main residence in childhood which was defined as domicile at one or more locations within a single county (City of Aberdeen as a single unit) for a minimum of eight years in the period up to 15 years of age. The same statistical methods were used as previously.

In order to tabulate all patients in the National Health Service (NHS) Central Register in Edinburgh it is necessary to know the individual's NHS number. These numbers are issued in Scotland at birth, or at later enumeration or entry to the country from abroad. Entries are routinely updated with changes in name and Health Board area provided that migrating patients register with a new general practitioner. ${ }^{4}$ Acheson $^{5}$ indicated that there were few incentives for patients to retain a record of their NHS number. Since the number is on the medical record wallet 
Table 1 Prevalence of $M S$ in north-east Scotland by diagnostic group and sex

\begin{tabular}{llc}
\hline & $\begin{array}{l}\text { No of patients } \\
\text { with MS }\end{array}$ & $\begin{array}{l}\text { Prevalence/100 000 } \\
\text { population* }\end{array}$ \\
\hline $\begin{array}{l}\text { Probable MS } \\
\text { Probable and early and }\end{array}$ & 324 & 74 \\
latent probable MS & 517 & 117 \\
All men & 232 & 110 \\
All women & 402 & 175 \\
All patients & 634 & 144
\end{tabular}

* Population in 1971 Census was 440 176: men 210250, women $229926 .{ }^{2}$

held by the general practitioner, we also asked for the NHS number, when we contacted them concerning the numbers of MS patients in their practice. Only about $40 \%$ of patients' NHS numbers obtained in this way and the rest by painstaking search through the nominal card index held by the NHS Local Medical Committees in each area. Eventually every patient in the current study was "flagged" in the NHS Central Register.

\section{Results}

A total of 472 patients remained from the 557 patients in the 1970 study (57 had died, 23 had left the area and the diagnosis was rejected in five). To these were added 144 new patients seen at hospital and 18 from general practitioner records. Fifty of these additional patients had been living in north-east Scotland on prevalence day in 1970 and at that time would have had suf-

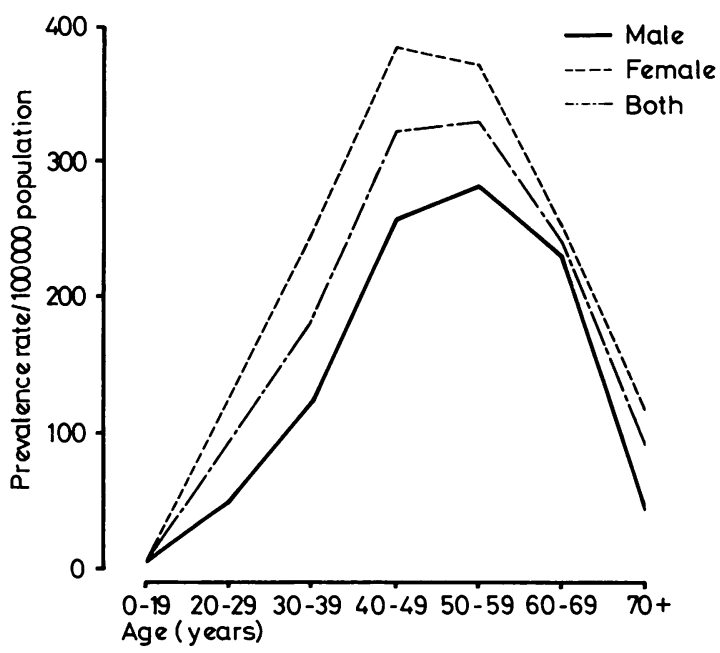

Fig 1 Age and sex specific prevalence of $M S$ in north-east Scotland on 1 December 1973. Based on the age and sex distribution of the whole Scottish population in 1971 Census. ${ }^{2}$

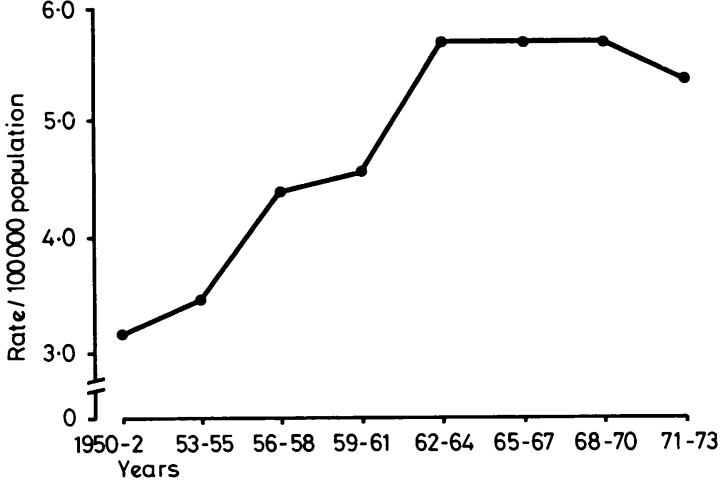

Fig 2 Incidence rates/100 000 population in three year periods for north-east Scotland 1950-1973.

ficient historical and clinical evidence to permit a diagnosis of MS bit they were not located in the earlier study.

On 1 December 1973, 634 patients with MS were living in north-east Scotland. The overall prevalence was 144 per 100000 population and even excluding possible MS patients the rate was greater than 1 per 1000 population (table 1). The mean age at onset of all patients was 33.8 years (range 11 to 61 ). The mean duration of disease was 15.3 years, and $12.2 \%$ had had the disease for more than 30 years and five patients for more than 50 years. The mean age of all patients on prevalence day was 48.6 years (range 14 to 87 ) and $95 \%$ of patients were aged 20 to 69 years. Using the age and sex distribution of the whole Scottish poulation, ${ }^{2}$ the age and sex specific prevalence rates for north-east Scotland have been calculated (fig 1). The highest rate for men, 282 per 100000 , was recorded for those aged 50 to 59 years and for women a rate of 384 per 100000 was obtained for those aged 40 to 49 years. The incidence rates per 100000 population for three year periods from 1950 to 1973 have been calculated (fig 2). The mean incidence rate for the 15 year period 1959 to 1973 was $5 \cdot 3$ per 100000 population.

\section{Prevalence by area of residence on}

1 December 1973

The prevalence of MS for all patients by county (fig 3) on prevalence day did not show a significant distribution but Aberdeen county had the highest rate (table 2). The distribution of all patients among the 28 area units (table 3 ; fig 4 and 5) is significantly different from expected $\mathrm{p}<001)$. Four areas had rates over 200 per 100000 and the highest was again area 16. Four 


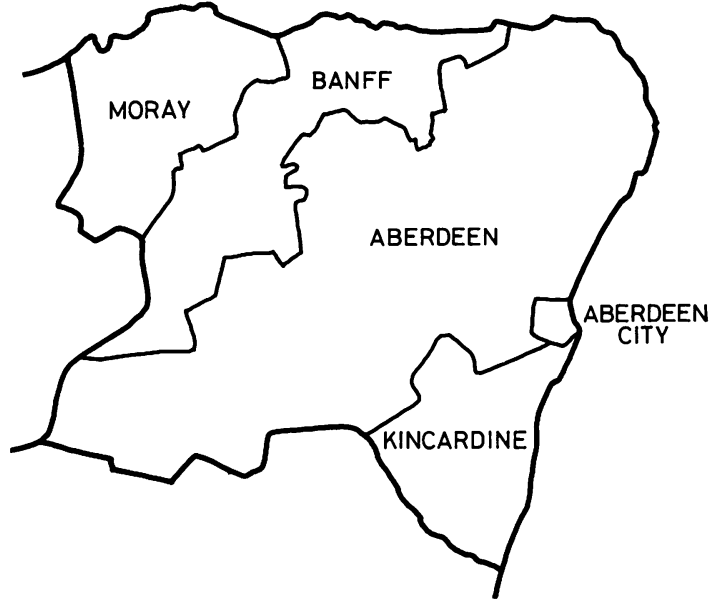

Fig 3 The counties of north-east Scotland.

adjacent wards of Aberdeen City (areas 7 to 10) had prevalence rates $50 \%$ above the overall mean, one in every 497 of the population being affected.

\section{Prevalence by area of birthplace}

Five hundred and one patients were born in north-east Scotland. Place of birth was unknown in 11 cases. Of the remaining 122 patients, nine were born in Orkney and Shetland, 69 elsewhere in Scotland, 32 elsewhere in the UK, and 12 abroad. The distribution by county showed a significant difference from expected (table 2). The highest rate was in Aberdeen county which had a significant excess compared to the rest of the region $\left(\chi^{2}=14.730 ; p<0.001\right)$. Rather fewer than expected were born in Kincardine but this was not significant.

Prevalence by area of main residence in childhood There were 497 patients who had spent at least eight years of their childhood up to the age of 15 in one of the counties, but 21 patients did not fit these criteria. Childhood addresses were unknown in 11 patients and the remaining 105 were elsewhere in Britain or abroad. The distribution of area of residence in childhood by county was significant at the $1 \%$ level (table 2). The figures differed little from area of birthplace and again Aberdeen county had a significant excess compared to the rest of the region $\left(\chi^{2}=16.217 ; \mathrm{p}<0.001\right)$.

\section{Discussion}

This second prevalence study of MS in northeast Scotland has confirmed that the disease

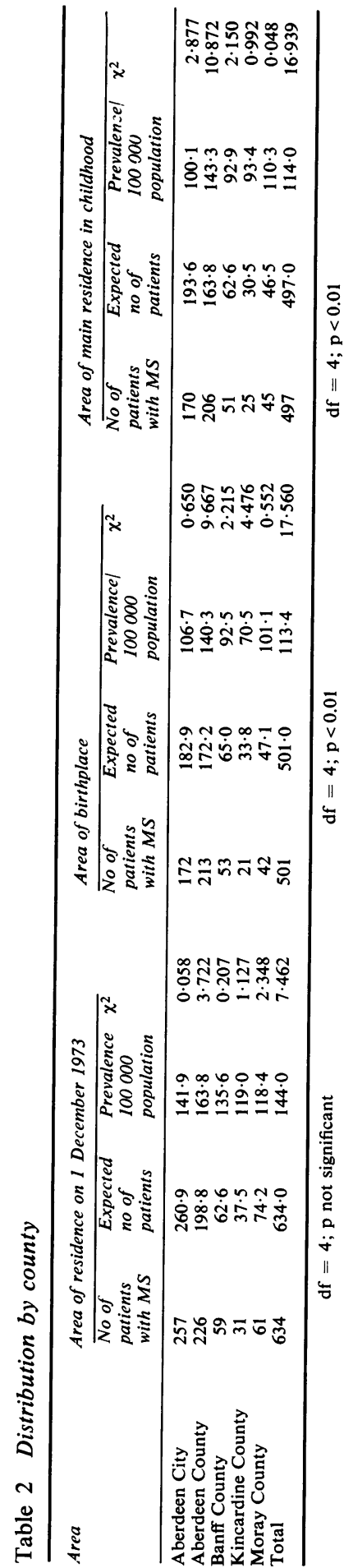


Table 3 Prevalence of MS by area of residence on 1 December 1973

\begin{tabular}{|c|c|c|c|c|c|}
\hline Area no & Population* & $\begin{array}{l}\text { No of } \\
\text { patients } \\
\text { with MS }\end{array}$ & $\begin{array}{l}\text { Expected } \\
\text { no of } \\
\text { patients }\end{array}$ & $\begin{array}{l}\text { Prevalencel } \\
100000 \\
\text { population }\end{array}$ & $\chi^{2}$ \\
\hline 1 & 9623 & 13 & 13.9 & $135 \cdot 1$ & 0.012 \\
\hline 2 & 9923 & 10 & $14 \cdot 3$ & $100 \cdot 8$ & $1 \cdot 010$ \\
\hline 3 & 18121 & 14 & $26 \cdot 1$ & $77 \cdot 3$ & $5 \cdot 156$ \\
\hline 4 & 11768 & 22 & 16.9 & $186.9+$ & $1 \cdot 252$ \\
\hline 5 & 17392 & 21 & $25 \cdot 0$ & 120.7 & 0.490 \\
\hline 6 & 21439 & 18 & 30.9 & 84.0 & 4.976 \\
\hline 7 & 15748 & 33 & $22 \cdot 7$ & $209 \cdot 6+$ & $4 \cdot 231$ \\
\hline 8 & 14507 & 31 & 20.9 & $213 \cdot 7 \dagger$ & $4 \cdot 410$ \\
\hline 9 & 11160 & 22 & $16 \cdot 1$ & $197 \cdot 1 \dagger$ & 1.811 \\
\hline 10 & 16248 & 30 & 23.4 & $184 \cdot 6 \dagger$ & $1 \cdot 590$ \\
\hline 11 & 19875 & 27 & $28 \cdot 6$ & $135.8 \dagger$ & 0.042 \\
\hline 12 & 15349 & 16 & $22 \cdot 1$ & $104 \cdot 2$ & $1 \cdot 419$ \\
\hline 13 & 14160 & 15 & $20 \cdot 4$ & $105 \cdot 9$ & $1 \cdot 177$ \\
\hline 14 & 10606 & 23 & $15 \cdot 3$ & $216.9 \dagger$ & $3 \cdot 388$ \\
\hline 15 & 20415 & 19 & $29 \cdot 4$ & $93 \cdot 1$ & $3 \cdot 334$ \\
\hline 16 & 10768 & 26 & $15 \cdot 5$ & $241 \cdot 5 \dagger$ & $6 \cdot 452$ \\
\hline 17 & 17027 & 27 & $24 \cdot 5$ & 158.6 & 0.163 \\
\hline 18 & 14635 & 23 & $21 \cdot 1$ & $157 \cdot 2$ & 0.093 \\
\hline 19 & 14220 & 28 & 20.5 & $196.9+$ & $2 \cdot 390$ \\
\hline 20 & 36130 & 55 & $52 \cdot 0$ & $152 \cdot 2$ & 0.173 \\
\hline 21 & & 23 & 22.0 & 150.9 & 0.011 \\
\hline 22 & 16537 & 16 & $23 \cdot 8$ & 96.8 & $2 \cdot 239$ \\
\hline 23 & 10 & 10 & 16.9 & 170.6 & 0.400 \\
\hline 24 & 11724 & 20 & $16 \cdot 9$ & $1 / 0 \cdot 6$ & 0.400 \\
\hline $\begin{array}{l}24 \\
25\end{array}$ & 11913 & 21 & $17 \cdot 2$ & $176 \cdot 3$ & 0.633 \\
\hline 25 & 14146 & 20 & $20 \cdot 4$ & $141 \cdot 4$ & \\
\hline 26 & 20050 & 30 & $28 \cdot 9$ & $147 \cdot 6$ & 0.012 \\
\hline 27 & 16343 & 20 & $23 \cdot 5$ & $122 \cdot 4$ & 0.383 \\
\hline 28 & 15107 & 11 & $21 \cdot 7$ & $72 \cdot 8$ & $4 \cdot 794$ \\
\hline Total & 440176 & 634 & $634 \cdot 0$ & $144 \cdot 0$ & $52 \cdot 041$ \\
\hline
\end{tabular}

* 1971 Census figures. ${ }^{2}$

$\dagger$ More than $25 \%$ above mean prevalence. $\mathrm{df}=27 ; \mathrm{p}<0.01$.

occurs there more frequently than in any other surveyed area with a comparable population. In Europe the only higher rate has been that found in Orkney and Shetland in a substantially smaller population. ${ }^{6}$ Whenever the prevalence of MS has been recorded in an area on two occasions the second study has revealed a higher rate. ${ }^{i-15}$ In north-east Scotland 50 patients were omitted in

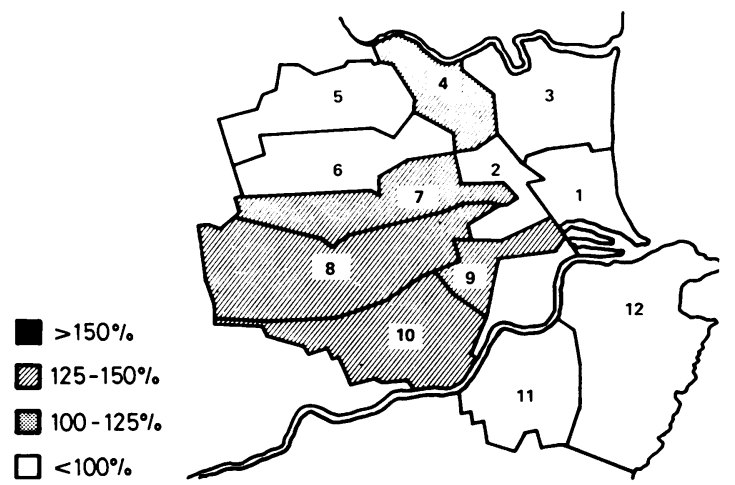

Mean rate for region $144 / 100000$

Fig 4 Prevalence of MS in the City of Aberdeen according to area of residence on 1 December 1973.
1970 who would have been eligible for inclusion. The revised prevalence in 1970 in retrospect is 138 per 100000 population. We suspect, therefore, that our 1973 rate of 144 per 100000 popu-

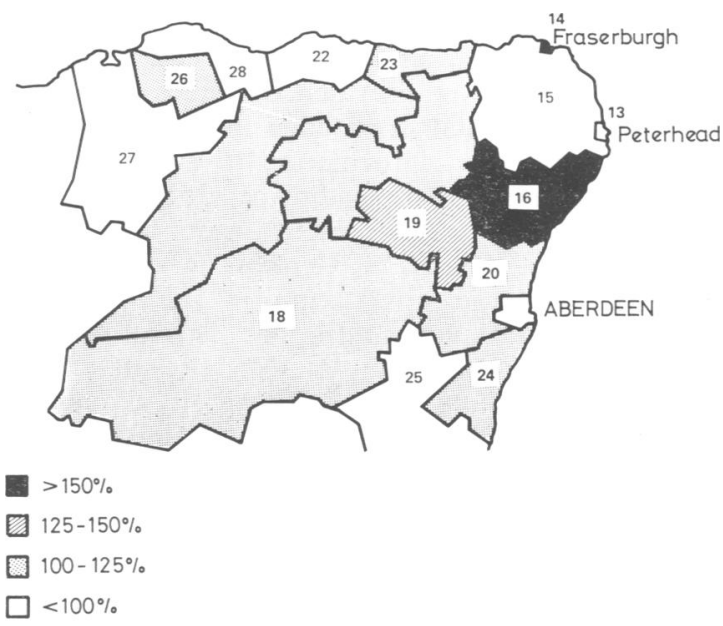

Mean rate for region $144 / 100000$

Fig 5 Prevalence of $M S$ in north-east Scotland according to area of residence on 1 December 1973. 
lation more accurately reflects the occurrence of MS in north-east Scotland than the figure we previously found in $1970 .^{1}$

The mean duration of disease on prevalence day is longer than in any other study, the nearest being that of 12.9 years in Turku, Finland. ${ }^{1 ;}$ Poskanzer et $a l^{17}$ have suggested that the mean life expectancy is twice the disease duration from onset to prevalence day. For the present study this period would be $30 \cdot 4$ years which approaches the predicted mean duration of at least 35 years found in the study of male US Veterans. ${ }^{18}$ The incidence of MS in north-east Scotland is also exceptionally high and has been stable for at least 15 years. A higher rate has only been recorded in the small Massachusetts community of Duxbury. ${ }^{19}$ The exceptional age specific prevalence rates indicate that among the 104000 people aged 40 to 59 years in north-east Scotland one in every 306 had MS on prevalence day.

The county of Aberdeen had the highest prevalence rate for area of residence on prevalence day, birthplace and main residence in childhood. This county also included area 16 which had the greatest prevalence in this and the earlier study. Since an environmental factor may be implicated in the aetiology of MS many years before clinical onset ${ }^{12} 20$ it seemed worthwhile studying area of main residence in childhood. However, the distribution was similar to that of area of birthplace, but more patients did spend their childhood in Kincardine and Moray than were born there, reflecting the fact that in the 1961 Census $^{3}$ only $38 \%$ of the Kincardine population and $52 \%$ of the Moray population had been born in these areas. If north-east Scotland is typical, in future prevalence studies examination of area of main residence in childhood will not add significant information to that obtained from studying area of birthplace alone.

All patients in the present study have been tabulated in the NHS Central Register. We receive automatic notification in the event of subsequent death or emigration. This procedure will facilitate the study of MS prevalence in north-east Scotland in the future, it will allow accurate survival rates to be determined and it will help assess the accuracy of the mortality data from the Registrar General for Scotland.

As long ago as 1950 Limburg $^{21}$ noted that Scotland had the highest death rate from MS in the world and this was confirmed in the subsequent period 1951 to $60 .{ }^{22}$ Our studies ${ }^{123}$ and those of Sutherland ${ }^{24}$ and Poskanzer et al ${ }^{6}$ have confirmed the high prevalence of MS in several geographical areas of Scotland. In both 1970 and
Table 4 Mean annual $M S$ death rate 1939-1972

\begin{tabular}{ll}
\hline Area & Rate/100 000 population* \\
\hline Scotland & $2 \cdot 9$ \\
North-east Scotland & $2 \cdot 8$ \\
Aberdeen City & $2 \cdot 6$ \\
Aberdeen County & $2 \cdot 8$ \\
Banff County & $2 \cdot 6$ \\
Kincardine County & 3.0 \\
Moray County & $3 \cdot 1$
\end{tabular}

* Obtained from 1951 Census. ${ }^{3}$

1973 in north-east Scotland the distribution of patients by area unit was significantly different from expected but of perhaps greater importance was the overall high prevalence rate. The question remains whether MS is more prevalent in north-east Scotland than elsewhere in Scotland. We think this is unlikely since the MS death rates for the whole of north-east Scotland and the individual counties are similar to the Scottish rate (table 4). With the possible exception of the outer Hebrides (Dean and Downie, personal communication) it seems likely that MS is common throughout Scotland.

\section{References}

1 Shepherd DI, Downie AW. Prevalence of multiple sclerosis in north-east Scotland. $\mathrm{Br} \mathrm{Med} \mathrm{J}$ 1978; 2:314-6.

2 General Register Office (Scotland). Census 1971 Scotland, Population Tables. Edinburgh: HMSO, 1974.

3 General Register Office (Scotland). Census 1961 Scotland, County Reports. Edinburgh: HMSO, 1963.

4 Hedley AJ, Alexander EA, Innes G. Patient identification and documentation of causes of death in a follow-up register. Health Bull (Edinb) 1977; 35:73-7.

5 Acheson ED. Medical Record Linkage: from the Oxford Record Linkage Study and the Unit of Clinical Epidemiology, Nuffield Department of Clinical Medicine, University of Oxford. London: Oxford University Press, for the Nuffield Provincial Hospitals Trust, 1967.

6 Poskanzer DC, Walker AM, Yonkondy J, Sheridan JL. Studies in the epidemiology of multiple sclerosis in the Orkney and Shetland Islands. Neurology (Minneap) 1976; 26, No 6 part 2: 14-7.

7 Georgi F, Hall P. Studies on multiple sclerosis frequency in Switzerland and East Africa. Acta Psychiatr Neurol Scand 1960; 35, suppl 147: 75-84.

8 Stazio A, Kurland LT, Bell L, Saunders M, Rogot E. Multiple sclerosis in Winnipeg, Manitoba; methodological considerations of epidemiologic survey. Ten-year follow-up of a community 
wide study and population resurvey. J Chronic Dis 1964; 17:415-38.

9 Fog M, Hyllested K. Shetland-Orkney-Faroe project. Acta Neurol Scand 1966; 42, suppl 19: 6-11.

10 Dean G. Annual incidence, prevalence and mortality of multiple sclerosis in white SouthAfrican-born and in white immigrants to South Africa. Br Med J 1967; 2:724-30.

11 Percy AK, Nobrega FT, Okazaki H, Glattre E, Kurland LT. Multiple sclerosis in Rochester, Minn. Arch Neurol 1971; 25:105-11.

12 Millar JHD. Multiple Sclerosis. A Disease Acquired in Childhood. Springfield, Illinois: Thomas, 1971.

13 Gudmundsson KR. Clinical studies of multiple sclerosis in Iceland. A follow-up of previous survey and reappraisal. Acta Neurol Scand 1971; 47, suppl 48: 5-78.

14 Broman T, Bergmann L, Andersen O, LindbergBroman A. Multiple sclerosis in Gothenburg. In: Leibowitz U, ed. Progress in Multiple Sclerosis: Research and Treatment. New York: Academic Press, 1972; 186-9.

15 Wikstrom J, Palo J. Studies on the clustering of multiple sclerosis in Finland $\mathrm{I}$ : comparison between the domiciles and places of birth in selected sub populations. Acta Neurol Scand 1975; 51:85-98.

16 Panelius M. Studies on epidemiological, clinical and aetiological aspects of multiple sclerosis.
Acta Neurol Scand 1969; 45, suppl 39: 7-82.

17 Poskanzer DC, Schapira K, Miller H. Epidemiology of multiple sclerosis in the counties of Northumberland and Durham. $J$ Neurol Neurosurg Psychiatry 1963; 26:368-76.

18 Kurtzke JF, Beebe G, Nagler B, Nefzger $M$, Auth T, Kurland LT. Studies on the natural history of multiple sclerosis. Arch Neurol 1970; 22:215-25.

19 Deacon WE, Alexander L, Siedler H, Kurland LT. Multiple sclerosis in a small New England community. $N$ Engl J Med 1959; 261:1059-61.

20 Alter $M$. Clues to the cause based upon the epidemiology of multiple sclerosis. In: Field EJ, ed. Multiple Sclerosis: a Critical Conspectus. Lancaster: MTP Press, 1977; 35-82.

21 Limburg C. The geographic distribution of multiple sclerosis and its estimated prevalence in the United States. In: Multiple Sclerosis and the Demyelinating Diseases, Assoc Res Nerv Ment Dis. Baltimore: Williams and Wilkins, 1950; 28: 15-24.

22 World Health Organisation. In: Epidemiological and Vital Statistics Report, 1966; 19:32-51.

23 Shepherd DI. In: Multiple Sclerosis in north-east Scotland. University of Aberdeen: MD Thesis, 1976.

24 Sutherland JM. Observations on the prevalence of multiple sclerosis in northern Scotland. Brain 1956; 79:635-54. 